\title{
Comparison of milk oxidation by exposure to LED and fluorescent light
}

\author{
C. Brothersen, ${ }^{1}$ D. J. McMahon, J. Legako, and S. Martini \\ Department of Nutrition, Dietetics, and Food Sciences, Utah State University, Logan 84322
}

\begin{abstract}
Light-induced oxidation of milk has been well studied. Exposure of milk to UV light facilitates the oxidation of fats to aldehydes, and the degradation of sulfur-containing amino acids, both of which contribute to off-flavors. In addition, vitamin $\mathrm{A}$ and riboflavin are easily degraded by UV light. These reactions occur rapidly and are exacerbated by bright fluorescent lights in retail dairy cases. The invention of white light-emitting diodes (LED) may provide a solution to this oxidation problem. In this study, fresh milk containing $1 \%$ fat and fortified with vitamin A and riboflavin was exposed to LED at 4,000 lx, or fluorescent light at 2,200 lx for 24 h. Milk samples exposed to LED or fluorescent light, as well as milk protected from light, were analyzed by a consumer acceptance panel, and a trained flavor panel. In addition, vitamin $\mathrm{A}$, riboflavin, and the production of volatile compounds were quantified. Exposure to light resulted in a reduction of cooked/sweet, milkfat, and sweet flavors and increased the intensity of butterscotch, cardboard, and astringency. In general, exposure to fluorescent light resulted in greater changes in the milk than exposure to LED even though the LED was at higher intensity. Consumers were able detect off-flavors in milk exposed to fluorescent light after $12 \mathrm{~h}$ and LED after $24 \mathrm{~h}$ of exposure. The riboflavin and vitamin A content was reduced by exposure to fluorescent light, whereas there was no significant reduction caused by LED compared with the non-light-exposed control. Production of hexanal, heptanal, 2-heptanal, octanal, 2-octanal nonanal, dimethyl sulfide, and caproic acid vinyl ester from the light-induced degradation of fats was significantly higher with fluorescent than LED. Production of these compounds was significantly higher with both light treatments than in the control milk. This study indicates that LED is less destructive to milk than fluorescent light.
\end{abstract}

Key words: milk, light oxidation

Received May 21, 2015.

Accepted December 13, 2015.

${ }^{1}$ Corresponding author: carl.brothersen@usu.edu

\section{INTRODUCTION}

Off-flavors develop when milk is exposed to near-UV and visible light from any source, such as sunshine, fluorescent light (FL), or light-emitting diodes (LED). These off-flavors primarily result from 2 types of photodegradation reactions involving singlet oxygen that reacts with AA and UFA (Min and Boff, 2002). Degradation of methionine and other sulfur-containing compounds produce flavors characterized as cabbage, mushroom, plastic-like, medicinal, and burnt (Harper and Brown, 1964; Allen and Parks, 1975). Oxidation of methionine to dimethyl disulfide was considered by Jung et al. (1998) to be primarily responsible for the light-induced off-flavor in skim milk. Light oxidation can hydrolyze fatty acids (Finley and Shipe, 1969) and produce aldehydes, ketones, and alcohols, such as npentanal, n-hexanal, and 1-octen-3-one (van Aardt et al., 2005b).

The off-flavors generated by photooxidation are readily apparent. A trained taste panel detected off-flavors in $2 \%$ fat milk stored in high-density polyethylene (HDPE) containers and exposed to 2,000 lx of FL for 15 min (Chapman et al., 2002). Nontrained consumers detected off-flavors in the milk after $2 \mathrm{~h}$ of light exposure. Packaging materials, fat, flavorings, and antioxidants can provide some protection against lightinduced degradation of milk (Mestdagh et al., 2005; van Aardt et al., 2005a).

Riboflavin (vitamin $\mathrm{B}_{2}$ ) absorbs light at wavelengths between 200 and $500 \mathrm{~nm}$ (Drossler et al., 2002). This excitation of riboflavin causes formation of a variety of free radicals that not only result in loss of the riboflavin, but can further react to degrade other compounds (Dimick, 1982; Choe et al., 2005). Garcia and Silva (1997) found 14 AA were photooxidized in the presence of riboflavin. Aliphatic AA are photooxidized by riboflavin to produce carbon dioxide and aldehydes, whereas tyrosine and tryptophan are degraded into indoles (Lu and Liu, 2002).

The extent of degradation of riboflavin and other components of milk resulting from photooxidation varies depending on the type of milk. Higher fat content decreases photooxidation probably because of decreased light penetration (deMan, 1981; Gaylord et al., 
1986a; Whited et al., 2002). The addition of cocoa and other colored flavorants also decreases photooxidation (Chapman et al., 1998). In contrast, homogenization increases degradation (Saidi and Warthesen, 1995) even though it causes more light scattering. Addition of antioxidants can provide some protection (Garcia and Silva, 1997; Hall et al., 2010), although adding the free radical scavenging antioxidant $\alpha$-tocopherol had no effect on vitamin A degradation in light-exposed milk (Smith and Berge, 1997).

Although riboflavin is light sensitive, it is now believed that naturally occurring chlorophyllic compounds in milk have a greater effect on photooxidation of milk (Airado-Rodríguez et al., 2011). This comes about because these tetrapyrroles can absorb light in the visible range including at wavelengths $>575 \mathrm{~nm}$. The $\beta$-carotene in milk can absorb light at lower wavelengths and provide some protection against photosensitizers such as riboflavin (Airado-Rodríguez et al., 2011).

When exposed to FL (e.g., $860 \mathrm{~lx}$ for $14 \mathrm{~h}$ at $4^{\circ} \mathrm{C}$ ), milk loses $24 \%$ of its vitamin A (Chapman et al., 1998). This degradation continues for at least $24 \mathrm{~h}$ of exposure and then appears to stabilize during further exposure (deMan, 1981). An early hypothesis on light-induced oxidation of vitamin A was that it undergoes initial reversible isomerism followed by irreversible isomerism (Smith et al., 1939).

The ability of different packing material to filter light and reduce off-flavors and vitamin degradation in milk has been investigated by Cladman et al. (1998), van Aardt et al. (2001), and Moyssiadi et al. (2004). Clear glass transmits $91 \%$ of FL compared with $57 \%$ for HDPE, $90 \%$ for clear polycarbonate, and only $4 \%$ for paperboard (Dimick, 1982). Three-layered (whiteblack-white) polyethylene terephthalate (PET) blocks light from 200 to $800 \mathrm{~nm}$ and can prevent photooxidation. Transparent 3-layered PET with an active oxygen-binding inner layer blocks light from 200 to 300 $\mathrm{nm}$ and transmits $<0.5 \%$ of light from 300 to $800 \mathrm{~nm}$. Transparent monolayer PET with a UV-absorbing additive blocks light from 200 to $400 \mathrm{~nm}$ and at higher wavelengths light transmission increases to $85 \%$ at 800 nm.

Use of LED for illuminating foods in retail stores is increasing and it has been asserted that using LED would decrease photooxidation of milk because of the difference in light spectrum of LED compared with FL. Whether those differences would be enough to prevent photooxidation of milk has not been shown. Intawiwat et al. (2013) recommended the total blocking of all visible light or at least minimizing light transmission at wavelength $<450 \mathrm{~nm}$ and $>650 \mathrm{~nm}$. The objective of our research was to compare flavor, riboflavin, and vitamin A degradation, and production of volatile compounds in milk exposed to FL or LED. To our knowledge, this is the first report on oxidative flavor development in milk exposed to LED.

\section{MATERIALS AND METHODS}

\section{Light Exposure and Sample Collection}

Pasteurized and homogenized milk containing $1 \%$ fat and fortified with vitamins A and D (Qualcon Specialty Products Inc., Waconia, MN) at a nominal $2.1 \times 10^{3} \mathrm{IU}$ and $4.2 \times 10^{2} \mathrm{IU}$ per liter, respectively, was collected at the Utah State University Creamery in 18.9-L (5-gal) capacity LDPE bags (General Films, Covington, $\mathrm{OH}$ ), which were contained within opaque, black, 2.0 mil bags (Waxie Sanitary Supply, San Diego, CA) to shield the milk from ambient light. The milk was transferred to standard $1.89 \mathrm{~L}$ (half gallon) HDPE containers under low ambient light conditions $(\sim 2 \mathrm{~lx})$. The containers were randomly divided into 3 groups. The control group was covered in aluminum foil to exclude light. The LED group was placed in a light box $(45 \mathrm{~cm} \times 152 \mathrm{~cm}$ and $76 \mathrm{~cm}$ high) illuminated with LED (International Light Technologies, Peabody, MN). The bottles were placed $20 \mathrm{~cm}$ apart, and the light intensity at the top of the bottles was 4,000 lx. The FL group was placed in a light box $(45 \mathrm{~cm} \times 152 \mathrm{~cm}$ and $76 \mathrm{~cm}$ high) illuminated with FL (Ecolux, General Electric, Fairfield, CT). The bottles were placed $20 \mathrm{~cm}$ apart, and the light intensity at the top of the bottles was 2,200 lx. Both light boxes were covered with aluminum foil to prevent exterior light from entering the box. All containers were stored at $4^{\circ} \mathrm{C}$. The experiment was repeated 3 times over 4 wk.

\section{Vitamin A, Riboflavin}

One container of milk from the control group was randomly selected at 0,12 , and $24 \mathrm{~h}$ (designated C0, $\mathrm{C12}$, and C24, respectively), and one container from the LED and FL groups was randomly selected at 12 and $24 \mathrm{~h}$ (designated LED12, LED24, FL12, and FL24) of exposure. A 40-mL aliquot from each container was transferred to a 50-mL high-clarity polypropylene tube (BD Falcon, Franklin Lakes, NJ), covered with aluminum foil and frozen to $-62^{\circ} \mathrm{C}$. When samples from all replicates were gathered they were shipped with dry ice to McNeil Scientific (St. Louis, MO), where they were thawed in the dark and analyzed for vitamin A (AOAC International, 2005a), and riboflavin (AOAC International, 2005b). 


\section{Consumer Acceptance Panel}

A consumer acceptance panel was conducted at the end of the 24-h test period of each replicate at the Utah State University Sensory Evaluation Laboratory using standard protocols and a balanced incomplete block design (Meilgaard et al., 1999) with 90 volunteer panelists. Two containers of milk were randomly selected from each group (C24, LED24, and FL24) at $24 \mathrm{~h}$, and 2 containers were randomly selected from each of the LED and FL groups at $12 \mathrm{~h}$ (LED12 and FL12). Upon selection, each bottle was covered in aluminum foil to exclude light and stored at $4^{\circ} \mathrm{C}$. At the end of the 24-h time period, the selected containers were transported to the Utah State University Sensory Evaluation Laboratory. The milk from the 2 containers of each time and exposure treatment was comingled, and a $20-\mathrm{mL}$ aliquot was dispensed into $60-\mathrm{mL}$ sample cups under low ambient light (15 to $40 \mathrm{~lx}$ ), covered with lids, and stored in the dark at $7^{\circ} \mathrm{C}$ until presented to panelists. The milk samples were evaluated for aroma liking, color liking, flavor liking, and overall liking on a 9-point hedonic scale, where $1=$ dislike extremely, $2=$ dislike very much, $3=$ dislike moderately, $4=$ dislike slightly, $5=$ neither like nor dislike, $6=$ like slightly, $7=$ like moderately, $8=$ like very much, and $9=$ like extremely.

\section{Descriptive Sensory Analysis}

One container of milk from the control group was randomly selected at 0,12 , and $24 \mathrm{~h}$ and frozen to $-29^{\circ} \mathrm{C}$. One container of milk from the LED and FL groups was selected at 12 and $24 \mathrm{~h}$ of exposure, covered in aluminum foil, and frozen to $-29^{\circ} \mathrm{C}$. All containers were stored at $-29^{\circ} \mathrm{C}$ until samples from all 3 replicates were collected. They were then shipped overnight with dry ice to the North Carolina State University Sensory Service Center for evaluation. Samples were kept frozen and wrapped in foil until analyzed. Milks were thawed while covered in foil, then dispensed into $60-\mathrm{mL}$ soufflé cups with 3-digit codes, lidded, and equilibrated to room temperature $\left(20^{\circ} \mathrm{C}\right)$ before evaluation.

Eight trained descriptive panelists (7 females, 1 male, ages 25 to $55 \mathrm{yr}$ ) each with $>150 \mathrm{~h}$ of descriptive analysis experience with dairy products, including milks and milk off-flavors, evaluated each milk in duplicate for selected flavor attributes: cooked/sweet aromatic, milkfat, butterscotch, cardboard, sweet taste, and astringency on a 0 - to 15-point scale using the spectrum descriptive analysis method (Meilgaard et al., 1999; Drake and Civille, 2003).

\section{Volatile Compounds}

One container of milk from the control group was randomly selected at 0,12 , and $24 \mathrm{~h}$, and one container from the LED and FL groups was randomly selected at 12 and $24 \mathrm{~h}$ of exposure. A $40-\mathrm{mL}$ aliquot from each container was transferred to a 50-mL high-clarity polypropylene tube (BD Falcon), covered in foil, and frozen to $-62^{\circ} \mathrm{C}$ until samples from all replicates were collected.

Prior to analysis, samples were thawed at refrigerated temperatures $\left(2\right.$ to $\left.4^{\circ} \mathrm{C}\right)$ overnight. Samples were then allowed to warm to room temperature for $45 \mathrm{~min}$ before volatile collection. In each sample, 10 $\mu \mathrm{L}$ of a $40 \mu \mathrm{g} / \mathrm{mL}$ solution of 4-methyl-2-pentanone (Sigma-Aldrich, St. Louis, MO) was added to serve as an internal standard. Volatiles were collected using solid-phase microextraction (SPME) similar to Havemose et al. (2007). A preconditioned DVB/CARPDMS fiber (Supelco, Bellefonte, PA) was exposed in sample vials above milk surfaces for $30 \mathrm{~min}$, whereas vials were agitated and heated to $45^{\circ} \mathrm{C}$. Extraction and injection of volatile compound was carried out using a Gerstel automated SPME sampler (MPS, Gerstal Inc., Linthicum, MD). Volatile compounds were separated using a VF-5ms capillary column $(30 \mathrm{~m} \times 0.25 \mathrm{~mm}$ $\times 1.00 \mu \mathrm{m}$; Agilent J\&W GC Columns, Amstelveen, the Netherlands) on a gas chromatograph (Agilent Technologies GC model 7890G, Santa Clara, CA). Ions within the 33 to $500 \mathrm{~m} / \mathrm{z}$ range were detected by mass spectroscopy (Agilent Technologies Model 5977A) in the electron impact mode at $70 \mathrm{eV}$. Chromatography data were collected in the selective ion monitoring/ scan mode. Ions were selected based on the presence of 3 primary ions from compounds of interest. An alkane standard mix (C8-C22; Supelco) was used to calculate expected linear retention indexes for compounds of interest. Volatile compound identity was validated by external standard comparisons of ion fragmentation patterns when possible. Relative abundances of each volatile compound were determined through the ratio of target compound areas and internal standard area, similar to Tansawat et al. (2013). All samples were analyzed in triplicate.

\section{Statistical Analysis}

Statistical analysis was conducted using the Proc Glimmix procedure of SAS (Version 9.3, Cary, NC). One-way ANOVA was used to evaluate the treatment effects. Differences were considered significant at $P<$ 0.05 . 
Table 1. Mean descriptive analysis scores ${ }^{1}$ for milk stored in the absence of light (control) or exposed to light from light-emitting diodes (LED) or fluorescent lights (FL) for 0, 12, or $24 \mathrm{~h}$

\begin{tabular}{|c|c|c|c|c|c|c|c|}
\hline \multirow[b]{2}{*}{ Attribute } & \multicolumn{3}{|c|}{ Control } & \multicolumn{2}{|c|}{ LED } & \multicolumn{2}{|c|}{$\mathrm{FL}$} \\
\hline & $0 \mathrm{~h}$ & $12 \mathrm{~h}$ & $24 \mathrm{~h}$ & $12 \mathrm{~h}$ & $24 \mathrm{~h}$ & $12 \mathrm{~h}$ & $24 \mathrm{~h}$ \\
\hline Cooked sweet & $3.1^{\mathrm{a}}$ & $3.0^{\mathrm{a}}$ & $2.5^{\mathrm{b}}$ & $2.4^{\mathrm{c}}$ & $2.2^{\mathrm{d}}$ & $2.5^{\mathrm{b}}$ & $2.2^{\mathrm{d}}$ \\
\hline Milk fat & $1.7^{\mathrm{ab}}$ & $1.8^{\mathrm{a}}$ & $1.6^{\mathrm{b}}$ & $1.7^{\mathrm{ab}}$ & $1.3^{\mathrm{c}}$ & $1.6^{\mathrm{b}}$ & $1.6^{\mathrm{b}}$ \\
\hline Butterscotch & $\mathrm{ND}^{2}$ & $1.0^{\mathrm{b}}$ & $1.9^{c}$ & $2.1^{\mathrm{d}}$ & $0.9^{\mathrm{b}}$ & $2.2^{\mathrm{e}}$ & $2.8^{\mathrm{f}}$ \\
\hline Cardboard & ND & ND & $0.8^{\mathrm{b}}$ & $1.8^{\mathrm{c}}$ & $3.1^{\mathrm{f}}$ & $1.9^{\mathrm{d}}$ & $2.6^{\mathrm{e}}$ \\
\hline Sweet taste & $2.3^{\mathrm{a}}$ & $2.3^{\mathrm{a}}$ & $2.2^{\mathrm{b}}$ & $2.2^{\mathrm{b}}$ & $1.8^{\mathrm{d}}$ & $2.2^{\mathrm{b}}$ & $1.9^{\mathrm{c}}$ \\
\hline Astringent & $1.9^{\mathrm{a}}$ & $2.0^{\mathrm{a}}$ & $2.0^{\mathrm{a}}$ & $2.1^{\mathrm{b}}$ & $2.4^{\mathrm{c}}$ & $2.1^{\mathrm{b}}$ & $2.4^{\mathrm{c}}$ \\
\hline
\end{tabular}

${ }^{\mathrm{a}-\mathrm{f}}$ Means within a row and with different superscripts differ $(P<0.05)$.

${ }^{1}$ Attributes scored on a 1- to 15-point universal intensity scale (Meilgaard et al., 1999).

${ }^{2} \mathrm{ND}=$ not detected

\section{RESULTS AND DISCUSSION}

\section{Descriptive Sensory Analysis}

Significant $(P<0.05)$ differences were found between the control and light exposed milks for all 6 attributes (cooked/sweet aromatic, milkfat, butterscotch, cardboard, sweet taste, and astringency) examined by the descriptive sensory panel. Compared with the control milk, light exposure slightly decreased cooked/sweet aromatic flavor, milkfat flavor, and sweet taste, and slightly increased astringency, while causing large increases in butterscotch flavor and cardboard flavor (Table 1). Light exposure time was also significant in causing flavor changes.

Mean flavor scores for the $\mathrm{C} 0$ milk (frozen and kept in the absence of light immediately after sampling) were 3.1 for cooked/sweet aromatic flavor, 1.7 for milkfat flavor, 2.3 for sweet taste, and 1.9 for astringency. Cardboard and butterscotch flavors were absent in the $\mathrm{C} 0$ milk. No change occurred in astringency in the control milk for $24 \mathrm{~h}$, and no change occurred in cooked/sweet aromatic, milkfat, cardboard, or sweet flavors for $12 \mathrm{~h}$. In contrast, a detectable butterscotch flavor developed in the control milk within $12 \mathrm{~h}$ with a score of 1.0, which increased to 1.9 after $24 \mathrm{~h}$. Because butterscotch flavor developed in milk that had virtually no exposure to light, this suggests that reactions that lead to development of butterscotch flavor are not initially generated by photooxidation. Exposure to FL accelerated the development of butterscotch flavor with scores of 2.2 and 2.8 being reached in 12 and 24 $\mathrm{h}$, respectively. Exposure to LED for $12 \mathrm{~h}$ also caused an increase in butterscotch flavor score to 2.1, but on further exposure the butterscotch flavor was no longer as apparent and the score had decreased to 0.9 and was not significantly different from the 12 -h control milk.

Except for butterscotch and cardboard flavors, very little effect of light exposure was observed, with the FL and LED milks in general following the trends of the control milk with only slight $(<0.5$ units) difference in flavor scores being detectable by the trained panelists (Table 1). Such small differences in flavor attributes of milk would probably not be noticeable by untrained panelists, so consumer liking would be driven primarily by the presence of cardboard flavor. As shown by others (Chapman et al., 2002; Intawiwat et al., 2010), development of photooxidation-induced flavors in milk occurs very rapidly, so having a cardboard flavor score of $\sim 2$ within $12 \mathrm{~h}$ of light exposure was not unexpected. Chapman et al. (2002) have shown that this flavor can be detected within $1 \mathrm{~h}$ of light exposure by trained panelists, although in those experiments the milk received 2,000 lx light exposure along the length of the bottles rather than from above the bottles in our work. Cardboard flavor scores continued to increase in both the FL and LED milks with the milk exposed to the LED for $24 \mathrm{~h}$ having slightly more $(P<0.05)$ cardboard flavor than the FL milk with scores of 3.1 and 2.6 , respectfully.

\section{Consumer Acceptance Panels}

Mean liking scores and significant differences $(P<$ 0.05 ) for the consumer acceptance panels are shown in Table 2. Light exposure for $24 \mathrm{~h}$ had no significant effect on aroma liking or color liking with pooled mean scores 5.4 and 6.4, respectively. It was unexpected that no difference in aroma liking was found as changes in volatile compounds were observed using gas chromatography. Panelists rated the control milk (stored in the absence of light for $24 \mathrm{~h})$ higher $(P<0.05)$ for both flavor liking and overall liking (6.4 and 6.3, respectively) compared with the light-exposed milk. Significant decreases in flavor liking occurred after 12 $\mathrm{h}$ of light exposure with faster change taking place in the FL milk in which flavor liking had dropped to 5.3, whereas the LED milk had a score of 5.8. After $24 \mathrm{~h}$ of light exposure, the LED milk had also dropped in flavor 
Table 2. Mean consumer liking scores ${ }^{1}$ for milk stored in the absence of light (control) or exposed to light from light-emitting diodes (LED) or fluorescent lights (FL) for 12 and $24 \mathrm{~h}$

\begin{tabular}{lccccccc}
\hline & \multicolumn{2}{c}{ Control } & & \multicolumn{2}{c}{ LED } & & \multicolumn{2}{c}{ FL } \\
\cline { 2 - 3 } \cline { 7 - 8 } \cline { 6 - 7 } Attribute & $24 \mathrm{~h}$ & & $12 \mathrm{~h}$ & $24 \mathrm{~h}$ & & $12 \mathrm{~h}$ & $24 \mathrm{~h}$ \\
\hline Aroma liking & $5.5^{\mathrm{a}}$ & & $5.4^{\mathrm{a}}$ & $5.4^{\mathrm{a}}$ & & $5.4^{\mathrm{a}}$ & $5.3^{\mathrm{a}}$ \\
Color liking & $6.2^{\mathrm{a}}$ & & $6.4^{\mathrm{a}}$ & $6.4^{\mathrm{a}}$ & & $6.3^{\mathrm{a}}$ & $6.5^{\mathrm{a}}$ \\
Flavor liking & $6.4^{\mathrm{a}}$ & & $5.8^{\mathrm{b}}$ & $5.3^{\mathrm{c}}$ & & $5.3^{\mathrm{c}}$ & $5.3^{\mathrm{c}}$ \\
Overall liking & $6.3^{\mathrm{a}}$ & & $5.9^{\mathrm{b}}$ & $5.4^{\mathrm{c}}$ & & $5.4^{\mathrm{c}}$ & $5.4^{\mathrm{c}}$ \\
\hline
\end{tabular}

${ }^{\mathrm{a}-\mathrm{c}}$ Means within a row and with different superscripts differ $(P<0.05)$.

${ }^{1}$ Attributes were scored on a 1 to 9 scale by 90 panelists where $1=$ dislike, extremely, $2=$ dislike very much, $3=$ dislike moderately, $4=$ dislike slightly, $5=$ neither like nor dislike, $6=$ like slightly, $7=$ like moderately,

$8=$ like very much, and $9=$ like extremely.

liking to 5.3 and was not significantly different $(P<$ 0.05) from the FL milk after $24 \mathrm{~h}$.

\section{Vitamin A and Riboflavin}

The initial level of vitamin A in the milk was $2.24 \times$ $10^{3} \mathrm{IU} / \mathrm{L}$ and riboflavin was $1.65 \mathrm{mg} / \mathrm{L}$. For the control milk, no significant change was found in vitamin A or riboflavin (Table 3) content during $24 \mathrm{~h}$ storage in the absence of light. When exposed to FL there was a $30 \%$ loss in vitamin A content within the first $12 \mathrm{~h}$ followed by a further slight decrease. However, there was no loss of vitamin A in the LED milk.

Intawiwat et al. (2013) recommended that to minimize photooxidation of milk the light exposure be minimized in both the 400 to $450 \mathrm{~nm}$ and 600 to 650 $\mathrm{nm}$ wavelength range, so as to prevent photooxidation of riboflavin and chlorophyllic compounds. They also found higher correlation between milk flavor and chlorophyll degradation than with riboflavin degradation. In addition to the reactions of these photosensitizers, it is also known that vitamin A content can decrease upon light exposure via photolysis. The greater loss of vitamin A content in the FL milk may relate to differences in emission spectra between FL and LED. Both riboflavin and chlorophyllic compounds absorb light in the 400 to $450 \mathrm{~nm}$ wavelength range that is emitted by both FL and LED, whereas chlorophyllic compounds also absorb light in wavelengths $>500 \mathrm{~nm}$ (Intawiwat et al., 2010) where there are more emission peaks in the
FL spectrum. Because $<10 \%$ loss of riboflavin occurred during the $24 \mathrm{~h}$ of $\mathrm{FL}$ exposure, this suggests that the loss of vitamin A is more related to the absorption of the higher wavelength light.

The differences in light-induced changes in milk between FL and LED is most likely related to differences in their spectra at wavelengths $>500 \mathrm{~nm}$ in which naturally occurring chlorophyll photosensitizers can absorb light but riboflavin does not. After 12-h light exposure, no significant reduction was found in riboflavin content of either the FL or LED milk, yet in both milks there was a significant increase in cardboard flavor. Carotenoids are known to protect against photooxidation, and in the FL milk a significant drop occurred in vitamin A content with 12-h light exposure. No change was found in the vitamin A content of LED milk, which also suggests differences in the wavelength of light provided by FL and LED.

\section{Volatile Compounds}

Among the various volatile compounds measured using SPME-GCMS, many were not affected by light exposure $(P>0.1$ and in many cases $P>0.6)$. This included some carboxylic acids (hexanoic, octanoic, and decanoic), alcohols (2-methyl-2 propanol and 2-ethyl1-hexanol), acetones (2-proponone, 2-butanone, 2-nonanone, and 4-methyl-2-heptanone), heterocylic compounds (ethyl benzene and ethenyl benzene), alkanes and alkenes (3-methylpentane, 2-methyl-1-pentene,

Table 3. Vitamin A and riboflavin concentration for milk stored in the absence of light (control) or exposed to light from light-emitting diodes (LED) or fluorescent lights (FL) for 0,12 , or $24 \mathrm{~h}$

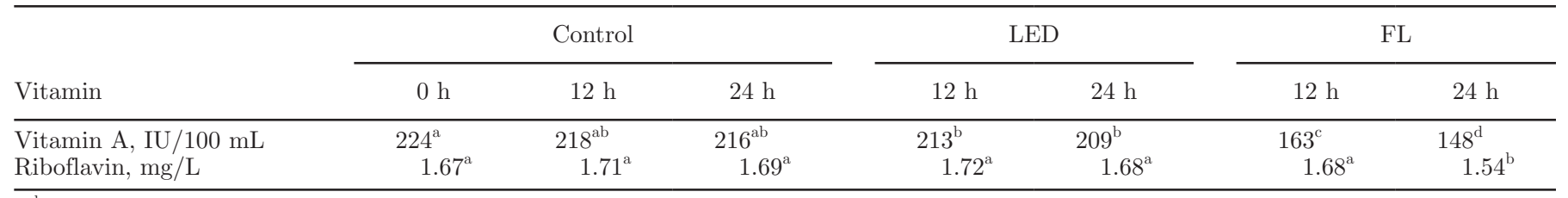

\footnotetext{
${ }^{\mathrm{a}-\mathrm{d}}$ Means within a row and with different superscripts differ $(P<0.05)$.
} 
2-thoxy-2methylpropane, heptane, and 2,4-dimethyl1-heptane), sulfur-containing compounds (dimethyl sulfide and dimethyl sulfone), along with 2-octenal and Tris-butyl ester orthoformic acid (data not shown).

Aldehydes were the compound group most influenced by light exposure as previously reported (Coppa et al., 2011; Villeneuve et al., 2013) and shown in Table 4. In the control milk, no significant $(P>0.05)$ change was found in hexanal, heptanal, 2-heptanal, octanal, 2-octanal, or nonanal during $24 \mathrm{~h}$ of storage in the absence of light. The relative abundance of each of these aldehydes increased with exposure to FL for $12 \mathrm{~h}$ but not with exposure to LED (Table 4). Lengthening the light exposure to $24 \mathrm{~h}$ further increased the level of these aldehydes in FL milk $(P<0.05)$ and a trend $(P<0.10)$ was observed for an increase in these aldehydes in the LED milk compared with the control milk. The aldehydes of highest relative abundance were hexanal and heptanal and at $24 \mathrm{~h}$ these were significantly higher $(P$ $<0.05)$ in the FL milk compared with the LED milk.

Other compounds that have been associated with light induced oxidation of milk (van Aardt et al., 2005a,b) and that were found to significantly increase with exposure to FL for $12 \mathrm{~h}(P<0.05)$, although still at low relative abundance, were 1-heptanol and 1-octanol and 1-octen-3-one. These compounds were below the detection limit in the control milk after $24 \mathrm{~h}$ and additional FL exposure to $24 \mathrm{~h}$ did not increase them any further. Exposure to LED for $24 \mathrm{~h}$ did not significantly increase 1-heptanol or 1-octanol but did increase 1-octen-3-one. Another compound that was below the detection limit in the control milk and significantly increased with $12 \mathrm{~h}$ exposure of the milk to FL was caproic acid vinyl ester.
Levels of this compound in LED milk was detectable after $12 \mathrm{~h}$, and a tendency $(P<0.10)$ was observed for it to continue to increase with $24 \mathrm{~h}$ exposure to a level about half that of FL milk. Aroma and taste descriptors and threshold values for all compounds detected, which were significantly changed by the light treatments are shown in Table 5.

Of the various volatile compounds that were measured after light exposure, the 2 that had highest relative abundance were hexanal and caproic acid vinyl ester. Hexanal remained at a relative abundance of 0.02 in the control milk that was shielded from light for 24 $\mathrm{h}$, whereas in the FL milk the hexanal level after 12 $\mathrm{h}$ was 0.93 and increased to 1.12 by $24 \mathrm{~h}$. In contrast, hexanal levels in LED after $12 \mathrm{~h}$ were only 0.12 and then increased to 0.56 after $24 \mathrm{~h}$. Similarly, caproic acid vinyl ester that was undetectable $(<0.01)$ in the control milk, increased to a relative abundance of 0.22 after $12 \mathrm{~h}$ exposure to FL, but was only at 0.02 in the LED milk. Other aldehydes that increased upon light exposure also were higher in the FL milk than the LED milk.

\section{CONCLUSIONS}

Therefore, flavor and quality advantages can be gained by using LED over FL in retail dairy cases, although with both lighting types, minimizing the time of light exposure is preferable. Our work suggests that LED that has less emission at wavelengths above 500 $\mathrm{nm}$ may provide further benefits in minimizing photooxidation reactions in milk and further research is needed to better understand the chemical changes that

Table 4. Relative abundance ${ }^{1}$ of volatile compounds (with $P<0.05$ ) in milk stored in the absence of light (control) or exposed to light from light-emitting diodes (LED) or fluorescent lights (FL) for 12 and $24 \mathrm{~h}$

\begin{tabular}{|c|c|c|c|c|c|c|c|c|c|}
\hline Compound & \multicolumn{3}{|c|}{ Control } & \multicolumn{2}{|c|}{$\mathrm{FL}$} & \multicolumn{2}{|c|}{ LED } & SEM & $P$ \\
\hline \multicolumn{10}{|l|}{ Aldehydes } \\
\hline Heptanal & $0.01^{\mathrm{c}}$ & $0.01^{\mathrm{c}}$ & $0.01^{\mathrm{c}}$ & $0.15^{\mathrm{ab}}$ & $0.22^{\mathrm{a}}$ & $0.02^{\mathrm{c}}$ & $0.09^{\mathrm{bc}}$ & 0.039 & 0.009 \\
\hline 2-Heptenal & $\mathrm{ND}^{2}$ & ND & $\mathrm{ND}$ & $0.02^{\mathrm{ab}}$ & $0.03^{\mathrm{a}}$ & $0.01^{\mathrm{c}}$ & $0.02^{\mathrm{bc}}$ & 0.005 & 0.001 \\
\hline Octanal & $0.01^{\mathrm{c}}$ & $0.02^{\mathrm{bc}}$ & $0.02^{\mathrm{bc}}$ & $0.04^{\mathrm{a}}$ & $0.05^{\mathrm{a}}$ & $0.02^{\mathrm{bc}}$ & $0.04^{\mathrm{ab}}$ & 0.010 & 0.012 \\
\hline 1-Heptanol & ND & ND & ND & $0.02^{\mathrm{a}}$ & $0.02^{\mathrm{a}}$ & $0.01^{\mathrm{b}}$ & $0.01^{\mathrm{b}}$ & 0.005 & 0.007 \\
\hline 1-Octanol & ND & $0.01^{\mathrm{ab}}$ & ND & $0.02^{\mathrm{a}}$ & $0.02^{\mathrm{a}}$ & $0.01^{\mathrm{ab}}$ & $0.01^{\mathrm{ab}}$ & 0.007 & 0.026 \\
\hline \multicolumn{10}{|l|}{ Ketones } \\
\hline 1-Octen-3-one & ND & ND & ND & $0.02^{\mathrm{b}}$ & $0.03^{\mathrm{a}}$ & $0.02^{\mathrm{b}}$ & $0.02^{\mathrm{b}}$ & 0.003 & $<0.001$ \\
\hline 2-Decanone & 0.01 & 0.01 & 0.01 & 0.01 & 0.01 & ND & 0.01 & 0.003 & 0.067 \\
\hline \multicolumn{10}{|l|}{ Esters } \\
\hline Caproic acid vinyl ester & ND & ND & ND & $0.22^{\mathrm{a}}$ & $0.27^{\mathrm{a}}$ & $0.02^{\mathrm{b}}$ & $0.14^{\mathrm{ab}}$ & 0.058 & 0.008 \\
\hline
\end{tabular}

${ }^{\mathrm{a}-\mathrm{c}}$ Means within a row and with different superscripts differ $(P<0.05)$.

${ }^{1}$ Based upon peak area relative to peak area of $40 \mu \mathrm{g} / \mathrm{mL}$ of internal standard 4-methyl-2-pentanon.

${ }^{2} \mathrm{ND}=$ not detected. 
Table 5. Aroma and flavor descriptors and threshold values for compounds detected in milk exposed to fluorescent light or light-emitting diodes

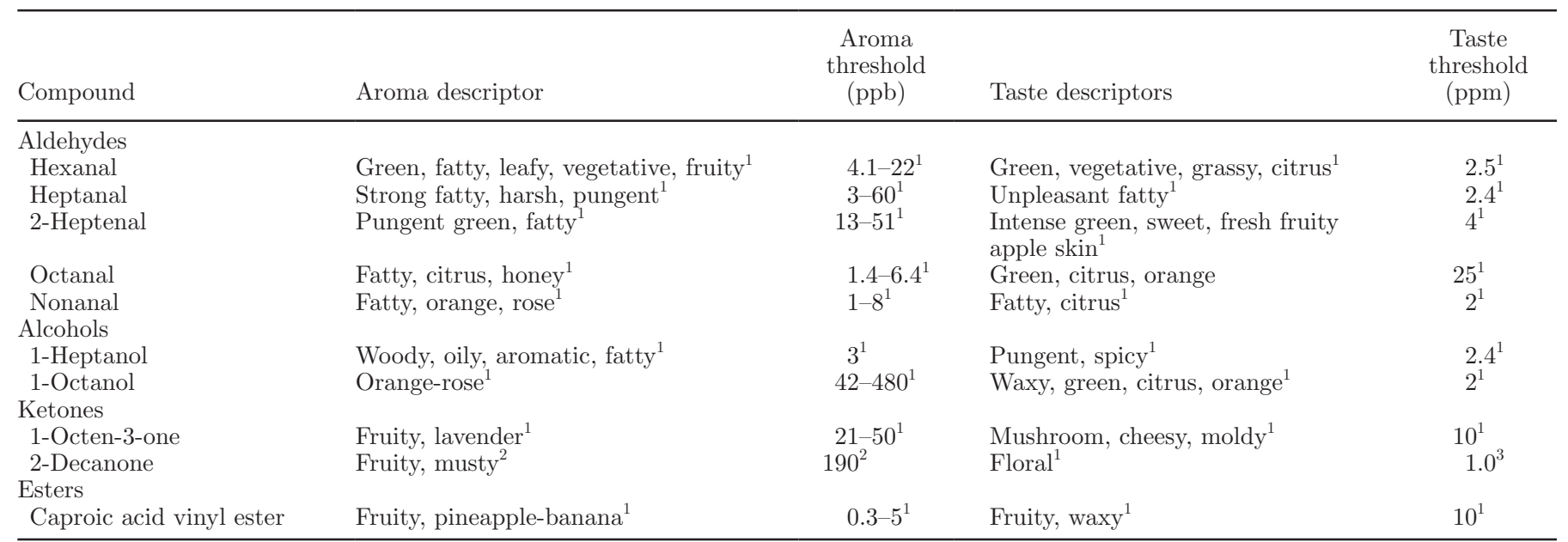

${ }^{1}$ Burdock, 2010.

${ }^{1}$ Cadwallader, 2007.

${ }^{3}$ Fazzalari, 1973.

lead to light-induced flavors and a decrease in consumer liking of milk.

\section{ACKNOWLEDGMENTS}

The authors thank Balasubramanian Ganesan (Utah State University, Logan) for statistical analysis. Partial funding for this research was provided by the National Dairy Council. This research was supported by the Utah Agricultural Experiment Station, Utah State University (Logan), and is approved as paper no. 8852 .

\section{REFERENCES}

Airado-Rodríguez, D., N. Intawiwat, J. Skaret, and J. P. Wold. 2011. Effect of naturally occurring tetrapyrroles on photooxidation in cow's milk. J. Agric. Food Chem. 59:3905-3914.

Allen, C., and O. W. Parks. 1975. Evidence for methional in skim milk exposed to sunlight. J. Dairy Sci. 58:1609-1611.

AOAC International. 2005a. Official method 2002.06. Retinyl palmitate (vitamin A) for fortified fluid milk. Official Methods of Analysis of AOAC International. 18th ed. AOAC Int., Gaithersburg, MD.

AOAC International. 2005b. Official method 970.56. Riboflavin (vi$\operatorname{tamin} B_{2}$ ) in foods and vitamin preparations. Official Methods of Analysis of AOAC International. 18th ed. AOAC Int., Gaithersburg, MD.

Berge, C., D. Smith, and J. Warthesen. 1988. Assessment of processing conditions on the location and stability of vitamin A in fluid milk. J. Dairy Sci. 70(Suppl. 1):60. (Abstr.)

Burdock, G. A. 2010. Fenaroli's Handbook of Flavor Ingredients. 6th ed. CRC Press, New York, NY.

Cadwallader, K. 2007. Measuring cheese flavor. Pages 401-433 in Improving the Flavour of Cheese, B. C. Weimer, ed. CRC Press, New York, NY.

Chapman, K. W., L. C. Rosenberry, D. K. Bandler, and K. J. Boor. 1998. Light-oxidized flavor development and vitamin A degradation in chocolate milk. J. Food Sci. 63:930-934.
Chapman, K. W., L. J. Whited, and K. J. Boor. 2002. Sensory threshold of light-oxidized flavor defects in milk. J. Food Sci. 67:27702773.

Choe, E., R. Huag, and D. B. Min. 2005. Chemical reactions and stability of riboflavin in foods. J. Food Sci. 70:R28-R36.

Cladman, W., S. Scheffer, N. Goodrich, and M. W. Griffiths. 1998. Shelf-life of milk packaged in plastic containers with and without treatment to reduce light transmission. Int. Dairy J. 8:629-636.

Coppa, M., B. Martin, P. Pradel, B. Leotta, A. Priolo, and V. Vasta. 2011. Effect of a hay-based diet or different upland grazing systems on milk volatile compounds. J. Agric. Food Chem. 59:4947-4954.

deMan, J. M. 1981. Light-induced destruction of vitamin A in milk. J. Dairy Sci. 64:2031-2032.

Dimick, P. S. 1982. Photochemical effects on flavor and nutrients of fluid milk. Can. Inst. Food Sci. Technol. J. 15:247-256.

Drake, M. A., and G. V. Civille. 2003. Flavor lexicons. Comprehensive Reviews in Food Science and Food Safety 2:33-40.

Drossler, P., W. Holzer, A. Penzkofer, and P. Hegemann. 2002. pH dependence of the absorption and emission behavior of riboflavin and aqueous solution. Chem. Phys. 282:429-439.

Fazzalari, F. A., ed. 1973. Compilation of Odor and Taste Threshold Data, ASTM Data Series DS 48. American Society for Testing and Materials, Philadelphia, PA.

Finley, J. W., and W. F. Shipe. 1969. Isolation of a flavor producing fraction from light exposed milk. J. Dairy Sci. 54:15-20.

Garcia, J., and E. Silva. 1997. Flavin-sensitized and photooxidation of amino acids present in a parenteral nutrition infusate: Protecton by ascorbic acid. J. Nutr. Biochem. 8:341-345.

Gaylord, A. M., J. J. Warthesen, and D. E. Smith. 1986a. Influence of milk fat, milk solids, and light intensity on the light stability of vitamin A and riboflavin in lowfat milk. J. Dairy Sci. 69:2779-2784.

Hall, N. H., T. M. Chapman, H. J. Kim, and D. B. Min. 2010. Antioxidant mechanisms of Trolax and asorbic acid on the oxidation of riboflavin in milk under light. Food Chem. 118:534-539.

Harper, W. J., and D. J. Brown. 1964. Light induced degradation of cysteine. J. Dairy Sci. 47:548-552.

Havemose, M. S., P. Justesen, W. L. P. Bredie, and J. H. Nielsen. 2007. Measurement of volatile oxidation products from milk using solvent assisted flavour evaporation and solid phase microextraction. Int. Dairy J. 17:746-752.

Intawiwat, N., M. K. Pettersen, E. O. Rukke, M. A. Meier, G. Vogt, A. V. Dahl, J. Skaret, D. Keller, and J. P. Wold. 2010. Effect of different colored filters on photooxidation in pasteurized milk. J. Dairy Sci. 93:1372-1382. 
Intawiwat, N., J. P. Wold, J. Skaret, E. O. Rukke, and M. K. Pettersen. 2013. Minimizing photooxidation in pasteurized milk by optimizing light transmission properties of green polyethylene films. J. Dairy Sci. 96:6818-6829.

Jung, M. Y., S. H. Yoon, H. O. Lee, and D. B. Min. 1998. Singlet oxygen and ascorbic acid effects on dimethyl disulfide and off-flavor in skim milk exposed to light. J. Food Sci. 63:408-412.

Lu, C. Y., and Y. Y. Liu. 2002. Electron transfer oxidation of tryptophan and tyrosine by triplet states and oxidized radicals of flavin sensitizers: a laser flash photolysis study. Biochim. Biophys. Acta 1571:71-76.

Meilgaard, M., G. V. Civille, and B. T. Carr. 1999. Sensory Evaluation Techniques, 4th ed. CRC Press, Boca Raton, FL.

Mestdagh, F., B. De Meulenaer, J. De Clippeleer, F. Devlieghere, and A. Huyghebaert. 2005. Protective influence of several packaging materials on light oxidation of milk. J. Dairy Sci. 88:499-510.

Min, D. B., and J. M. Boff. 2002. Chemistry and reaction of singlet oxygen in foods. Comprehensive Reviews in Food Science and Food Safety 1:58-72.

Moyssiadi, T., A. Badeka, E. Kondyli, T. Vakirtzi, I. Savvaidis, and M. G. Kontominas. 2004. Effect of light transmittance and oxygen permeability of various packaging materials on keeping quality of low fat pasteurized milk: Chemical and sensorial aspects. Int. Dairy J. 14:429-436.

Saidi, B., and J. J. Warthesen. 1995. Effect of heat and homogenization on riboflavin photolysis in milk. Int. Dairy J. 5:635-645.

Smith, D. E., and C. B. Berge. 1997. The effect of two antioxidants on the light stability of vitamin A in fluid milk. Milchwissenschaft $52: 551-554$.
Smith, E. L., F. A. Robinson, B. E. Stern, and F. E. Young. 1939 Studies in the stability of vitamins A and D. II The effect of light on vitamin A. Biochem. J. 33:207-212.

Tansawat, R., C. J. Maughan, R. E. Ward, S. Martini, and D. P. Cornforth. 2013. Chemical characterisation of pasture- and grain-fed beef related to meat quality and flavour attributes. Int. J. Food Sci. Technol. 48:484-495.

van Aardt, M., S. E. Duncan, J. E. Marcy, and T. E. Long. 2005a Aroma analysis of light exposed milk stored with and without natural and synthetic antioxidants. J. Dairy Sci. 88:881-890.

van Aardt, M., S. E. Duncan, J. E. Marcy, T. E. Long, and C. R Hackney. 2001. Effectiveness of poly(ethylene terephthalate) and high-density polyethylene in protection of milk flavor. J. Dairy Sci 84:1341-1347.

van Aardt, M., S. E. Duncan, J. E. Marcy, T. E. Long, S. F. O'Keefe, and S. R. Nielsen-Sims. 2005b. Effect of antioxidant ( $\alpha$-tocopherol and ascorbic acid) fortification on light-induced flavor of milk. J. Dairy Sci. 88:872-880.

Villeneuve, M.-P., Y. Lebeuf, R. Gervais, G. F. Tremblay, J. C. Vuillemard, J. Fortin, and P. Y. Chouinard. 2013. Milk volatile organic compounds and fatty acid profile in cows fed timothy as hay, pasture, or silage. J. Dairy Sci. 96:7181-7194.

Whited, L. J., B. H. Hammond, K. W. Chapman, and K. J. Boor. 2002. Vitamin A degradation and light-oxidized flavor defects in milk. J. Dairy Sci. 85:351-354. 